Hanna Mykhailichenko, Doctor of Economics, Professor, Kyiv National University of Trade and Economics, 19, Kyoto str., Kyiv, 02156, Ukraine

ORCID: 0000-0001-7066-6527

ResearcherID: 56074365500

Serhii Kravtsov, Candidate of Science of State Administration, Docent, Kyiv National University of Trade and Economics, 19, Kyoto str., Kyiv, 02156, Ukraine, ORCID: 0000-0002-2016-1974

Yulia Zabaldina, Candidate of Science of Economics, Docent, Kyiv National University of Trade and Economics, Ukraine, 19, Kyoto str., Kyiv, 02156, Ukraine, ORCID: 0000-0003-2741-5604

\title{
BRANDING EVENT TOURISM PROGRAMS IN UKRAINE
}

The article deals with the sense and structure of a tourism destination event portfolio. The theoretical foundation of the planning process for Ukrainian destinations event portfolio destinations as a component of their tourism product has been carried out. The goals of forming a destination's event portfolio within the framework of the tourism product strategy and marketing strategy are determined. The factors of decision making about the structure of an event portfolio, dynamics of measures are highlighted. Proportionality of Ukrainian `s destinations event portfolio is analyzed.

Keywords: destination, events, event tourism, event portfolio, tourist product, hallmark, tourist flow, tourist arrivals.

Relevance of research topic. Ukrainian touroperator's companies are searching necessary options for a competitive product in the international market. The national product has become event tourism, which has been developing rapidly in the recent years. «Made in Ukraine» has become a new national product brand «Ukraine. NOW» and provides recognition in the foreign markets of the world leaders - tourist suppliers. The main slogan of Ukrainian tourism should be: «Ukraine is the Best Tourist Friendly Destination».

Analysis of recent researches and publications. There are different criteria for classification of the events. The basic one classifies the events as planned and unplanned. Planned events are the subject of study of event management and they require setup, management, executives and certain length of time. Unplanned events 
are accidents, natural disasters, etc., and they will not be taken into consideration. If the events are classified according to their size and scope, it is possible to distinguish the following four types: mega-events (high tourist demand and high value), hallmarkevents (high tourist demand and high value), regional events (periodic and one-time) (medium tourist demand and medium value) and local or community events (periodic and one-time) (low tourist demand and low value) [1].

Formulation of the problem. The increasing competitive pressures brought on by globalization are forcing business professionals to find new ways to engage tourists. There are many definitions of event marketing. It is defined as the marketing discipline focused on face-to-face interaction via live events, trade shows and corporate meetings among other event types. Others define it as designing or developing a «live» themed activity, occasion, display, or exhibit (such as a sporting event, music festival, fair, or concert) to promote a tourism product of tourism destination.

The peculiarity of the created tourist product of the event-tourism market is the strengthening of the use of traditional cognitive tourism resources and tourist infrastructure of the main attractive destinations. So, 95,8\% of foreign tourists has positive impression from visiting Kyiv [2]. The most beautiful tourist attraction in Kyiv is historical and architectural monument, museums, religious and cultural objects.

Department of Tourism and Promotions of Kyiv State Administration develop and regulate Official Tourist Information Site for visiting the city of Kyiv (http://www.visitkyiv.travel/). All information on the city are presented in this site: monuments, exhibitions, events, maps, transport and a tourism service to help tourist prepare trip. Internet is the most important tool to attract tourist and to promote tourism destination (about 37\% tourists have information sources about Kyiv as a tourist attraction from Internet).

The Internet is the global 'network of networks» of interlinked computers operating on a standard protocol which allows data to be transferred between them. As an information exchange system, the most important aspect of the Internet is its connectivity, the ability to allow everyone to access the network. The potential of using the Internet for marketing activities is derived from its general use as an information exchange system in the digital age.

The information can be stored, indexed, retrieved, restructured and redistributed automatically by software and without human intervention. The Internet connects companies with companies, companies with customers, and people with people without regard to time, space and hardware/ software platforms.

Art, literature, gastronomy, music - the festival movement in Kyiv is gaining momentum. Various platforms (indoors and outdoors) alternately or simultaneously gather thousands of visitors. With the number of visitors increasing, the geography of guests is also expanding: Ukraine, Europe.

TOP-5 large-scale festivals that gathering thousands of visitors:

1. «Atlas Weekend Music Festival» was founded in 2015. Its main goal is development of festival culture in the country, attraction of foreign tourists to Ukraine 
and popularization of Ukrainian music in the world. Atlas Weekend 2017 has gathered more than 300000 visitors within 5 days.

2. «Kraina Mriy» is an international festival of ethnic music founded in 2004 with the aim of asserting Ukrainian national identity and presenting the best representatives of Ukrainian and world music. Since 2004 the festival has been attended by about 1 million people from more than 30 countries of the world.

3. «GOGOLFEST» is an annual multidisciplinary international festival of contemporary art. The program of the festival consists of five directions: theatre, music, cinema, literature and visual arts. Its audience is about 120000 people.

4. «Ulichnaya Eda» - its main goal is changing the attitude to street food, improving the culture of its cook and consumption, and promoting domestic food producers. The audience is about 55000 visitors within two days.

5. «International Book Arsenal Festival» is the largest event in Eastern Europe combining literature and art. Each year more than 200 outstanding Ukrainian and international writers, artists and experts of the book market take part in the festival. The audience for five days in 2017 was over 60000 visitors [11].

Attending of events is one of the important purposes to visit Kyiv by foreign tourists. In 2017 Kyiv host a lot of international events: International Ice Hockey Federation World Championship Division I, Wizz Air Kyiv City Marathon, Eurovision-2017 Song Contest, European Diving Championships and others. This was the second time the contest took place in Kiev, after 2005, as well as the fourth Eurovision event, after the Junior Eurovision Song Contest in 2009 and 2013. The contest consisted of two semi-finals on 9 and 11 May, and a final on 13 May 2017.

Hosting the contest open the door to other large-scale international events. The host city proves its ability to organize such events, improve its infrastructure, build some contacts, and gain experience. All this may lead to more income in the future.

Organizing the contest is not necessarily a burden even from a narrow shortterm perspective. Expenditures in other host countries were often inflated because the contest's profitability was never a priority for them. They viewed it as a chance to improve their international image and focused on staging a spectacular show.

Ukraine's poor international image has traditionally created low expectations among visitors to the country, and this trend was very much evident among Eurovision guests. Just over $47 \%$ of survey respondents said Kyiv had surpassed their expectations, while a massive $92 \%$ voiced their readiness to return to Ukraine. Just 10 visitors, or less than one percent of those surveyed, expressed disappointment at their experiences in Kyiv. When asked to identify the things that had impressed them the most, the top responses were the Ukrainian people (73\%) and Ukrainian culture (45\%). The biggest negatives were poor public transport infrastructure (26\%) and a perceived lack of English-language skills (18\%). As Ukraine seeks to engage with the international community, these results are worth dwelling on. Expensive media PR campaigns can certainly help to boost Ukraine's international profile, but enticing 
people to visit Ukraine may actually be one of the most cost effective ways of improving outside perceptions of the country [3].

The Eurovision Song Contest was widely seen as an opportunity for Ukraine to underline the country's European credentials, and survey results indicate that the event lived up to its billing. International opinion polls of European Union citizens generally identity little if any enthusiasm for future Ukrainian EU membership, but Eurovision visitors were positively bullish on the subject. A massive $54 \%$ of respondents saw Ukraine joining the EU within five years, while 19\% opted for the slightly more realistic timeframe of a decade. Just $1 \%$ said they did not see any EU future for Ukraine, making this the most Euro-optimistic survey in Ukrainian history. While these results doubtless owed much to the intoxicatingly festive mood generated by Eurovision, they do serve as a reminder that visitors to Kyiv are generally surprised and impressed by how quintessentially European the city is. Indeed, 57\% of respondents explained their belief in Ukraine's future EU membership by pointing to the country's European credentials, while 64\% said their time in Kyiv had made them more enthusiastic about Ukraine's EU membership ambitions [4].

The survey also revealed the continuing cost of negative international media coverage on perceptions of Ukraine. When asked to cite the key obstacles to Ukraine's EU integration, the most popular answer was corruption (45\%). Far fewer respondents (37\%) identified the on-going war with Russia, while more than a quarter (27\%) pointed to Ukraine's oligarchs as a major barrier to closer ties with the European Union. It is highly unlikely that Eurovision visitors encountered any first-hand evidence of government corruption and nefarious oligarch influence during their short period in the country. Instead, their responses serve as a reminder of the influence exerted by endless coverage of Ukraine's corrupt elite. This is the harsh reality facing all those working to improve Ukraine's international standing. Kyiv managed to dazzle and delight its Eurovision visitors, but until the country's political classes stop attracting damaging headlines, Ukraine will continue to fall short in its bid to create a positive image and establish itself as an exciting new addition to the European ensemble.

There are various ways to increase the market in the Kyiv tourism destination. The use of a brand name in getting the public's attention works well or method of regional cooperation in tourism, however, the use of advertising as the primary means of success requires a carefully analysis of the tools in the fields of scientific, social and economic behavior. Advertising is defined as the activity or profession of producing advertisements for commercial products or services.

There is a huge variety of the events that can be offered to the tourists in Kyiv tourism destination and it is hard to evaluate which can be the most attractive for them. It can be sport events, concerts or big outdoor festivals, conferences and business meetings, fashion shows, fill festivals, celebrations, trade fairs, religious event or local traditional celebrations. That is the reason why it is crucial to understand which type of the event can be the most interesting for the tourists in the questionnaire, where 
respondents were asked which types of the events they visit. According to the respondents answers the most popular events among them were exhibitions, conferences and meetings, concerts, food festivals and trade fairs. However, they visit all of the mentioned events (figure 1.).

The type of the events that are the most visited in Kyiv by tourists are concerts. That is why it makes sense to develop event product that respondent visit a lot but at the same time keep offering concerts and keep them up to date with the current trends. Some studies of the demand for the event show that Ukrainian prefers rock or pop music and they most often visit cinemas. The data about tourists' preferences should be considered during the development of the new event tourism product.

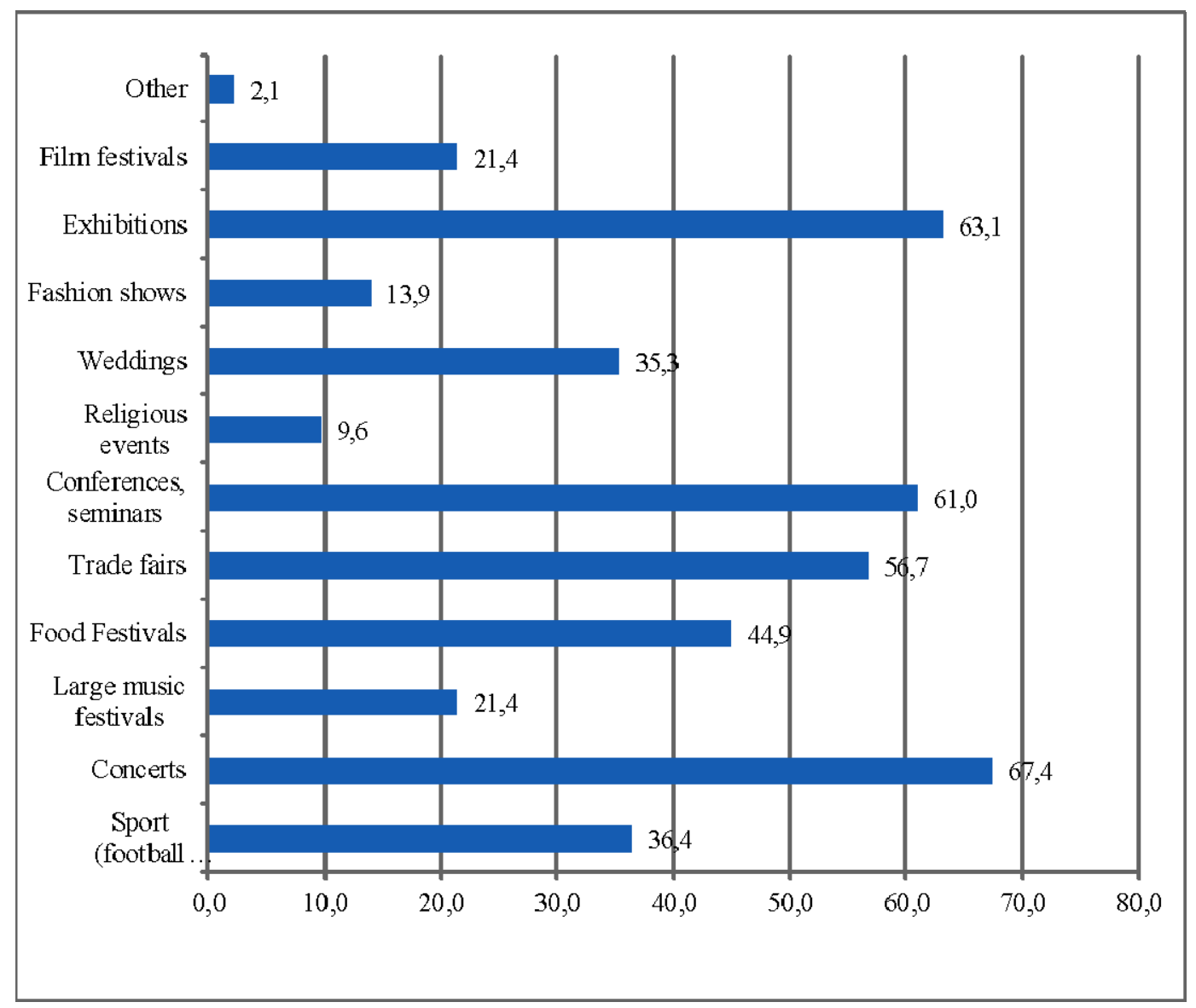

Figure 1. Results for the question «Which events you visit in Kyiv?»

Source: [refined by author based on 2-3].

Before investing a lot of time and money into the event, it is important to research its concept and to evaluate the likelihood of its success. It is possible to achieve by discovering other similar events that have been held locally or in another location. Any available market research about these events in terms of audience participation and community acceptance should be considered. Throughout the research, it will become possible to define the viability of the event for the audience. Then, the event can be scheduled with the confidence, and implemented and facilitated it in the most appropriate and effective way. 
It is important to establish a committee with identified roles and responsibilities, or share the workload with professional staff. Dependent on the nature and scope of the event, seek the services of a company to help in the planning and management of the event, or some components of the event. A pre-determined fee will apply. Using an external organisation to manage or partly manage the event does not diminish responsibility to fulfil obligations outlined in this guide.

Other questions should relate to the staging of the event. It can include: rate the parking ease and availability; how did you find out about this event; how do you think we could improve the promotion; did you find the program enjoyable; please rate the catering at the event. Feedback methods need to be quick and easy for participants to access and answer. They also need to be measurable and useful for the event organisers. Suitable methods could include feedback surveys, roving evaluators talking to participants and collection of hard data such as attendance numbers.

When the event is over, it is required to organise a debriefing to review all aspects of the experience. Debriefing is a process whereby the event stakeholders have the opportunity to discuss what worked, what didn't, why it didn't work and how it could be improved. All stakeholders should be involved in this forum including events' coordinators, sponsors, volunteers, security, vendors, performers and staff. It should be viewed as a worthwhile experience with recommendations greatly assisting the planning for the next event. Some points to discuss in the debrief: list of what was successful or worked well; list of what was not successful or did not work well; list of recommendations for the whole event.

It is important to acknowledge the hard work of all the stakeholders involved in the event. Regardless to the extent of their contribution, it is essential to let staff and volunteers know that their efforts are appreciated. It is a good idea to plan an informal gathering for staff, to give them an opportunity to talk about the event in a informal setting, and in turn give the opportunity to facilitate a feedback forum. Don't forget to have a budget for some catering during the debrief as a sign of appreciation. Don't forget to send out a letter or certificate of appreciation with some event photos for sponsorship.

Conclusion. An event marketing plan is required to detail how to promote the event. The plan must describe how the public will know about the event. It should describe all the promotional opportunities that will be used for the event. The plan should include who is responsible for each promotional activity or item and the proposed date for completion. List of marketing activities which organiser may engage for the event consists of advertising, media, banner, online tourism and event websites, direct mail.

Promotion is a key factor for the success of a special event. The main purpose that promotion serves is to attract participants, spectators or both groups to the event. It is essential therefore that the efforts made by many people over many months to organise a special event. Promotion is also important to the sponsor, if one exists. The objective of the sponsors is to achieve as much exposure of their name, logo and other 
properties as possible. Sponsors, therefore, have a keen interest in pre-event promotion and in the promotion that can be achieved on the day through erecting signage and product displays in view of all participants.

Department of Tourism and Promotions of Kyiv State Administration develop and regulate the activity of Tourist Information Centres. Department develops and regulates Official Tourist Information Site for visiting the city of Kyiv (http://www.visitkyiv.travel/) [4]. Department develops Kyiv Pass to attract foreign tourists. A smart card for tourists is available for buying as well. The card allows the holders to visit around 40 most popular sights of the city (museums, cultural objects, art galleries and clubs) whilst saving money and time. Department also represents each year Kyiv in international tourism exhibitions such as Ukraine International Travel Market (UITM) and Ukraine International Travel and Tourism Exhibition (UITT).

The festival movement in Kyiv (art, literature, gastronomy, music) is gaining momentum. Various platforms (indoors and outdoors) alternately or simultaneously gather thousands of visitors. While the number of visitors increasing, the geography of guests is also expanding: Ukraine, Europe, the USA. TOP-5 large-scale festivals that gather thousands of visitors are: Atlas Weekend Music Festival, Kraina Mriy, International Book Arsenal Festival, Ulichnaya Eda, GOGOLFEST. Foreign tourists visiting Kyiv find the attendance of the events one of the most important purposes of their trip.

Promotional activity is not a constant process, thus, it has various purposes over time, and the main communication means are: advertising, sales promotion, public relations and professional sales. Responsible for the promotion of Kyiv tourism destination is Department of Tourism and Promotions of Kyiv State Administration. It formulates a detailed marketing and promotional plan for the sector taking into account the quality and quantity of tourism products, the diversity of domestic, regional and international source markets, image and positioning, branding, quality and distribution of promotional materials (including e-marketing), institutional mechanisms for marketing and promotion of public-private partnership.

\section{REFERENCES}

1. Getz, D. (2008). Event tourism: Definition, evolution, and research, Tourism Management, vol. 29, pp. 403-428.

2. Sociological research of tourist flows to Kyiv. Executor: center for independent sociological research «OMEGA» [Electronic resource] available at: http://omega-research.com.ua.

3. Department of Tourism and Promotions [Electronic resource]. - Available at: http://www.visitkyiv.travel.

4. Brand Ukraine Eurovision Boost [Electronic resource]. - Available at: http://bunews.com.ua/society/item/eurovision-boosts-brand-ukraine. 